\title{
Globe
}

Revue internationale d'études québécoises

\section{Le Québec, société plurielle en mutation?}

\section{Julien Harvey}

Volume 1, numéro 1, 1998

Raisons communes

URI : https://id.erudit.org/iderudit/1000118ar

DOI : https://doi.org/10.7202/1000118ar

Aller au sommaire du numéro

Éditeur(s)

Globe, Revue internationale d'études québécoises

ISSN

1481-5869 (imprimé)

1923-8231 (numérique)

Découvrir la revue

Citer cet article

Harvey, J. (1998). Le Québec, société plurielle en mutation? Globe, 1(1), 40-51. https://doi.org/10.7202/1000118ar d'utilisation que vous pouvez consulter en ligne.

https://apropos.erudit.org/fr/usagers/politique-dutilisation/ 


\title{
Le Québec, société plurielle en mutation? *
}

\author{
Julien Harvey, s.j.
}

Amorcer la discussion de ce colloque ${ }^{* *}$ pourrait signifier vérifier une fois de phus si lidentité collective du Québec est vraiment devenue territoriale ou si elle est toujours ethnique, ou encore si l'évolution de la société plurielle, surtout à Montréal, se fait par convergence culturelle, par juxtaposition multiculturelle ou encore par évolution lente vers l'assimilation anglaise ou française des minorités. On pourrait aussi explorer une fois de plus les limites du pluralisme, la limite de tolérance avant l'atomisation.

Les réflexions que je voudrais plutôt soumettre ̀̀ la discussion aujourd'hui tracent quelques grandes lignes du

* Face à texte posthume qui n'a pas été totalement peaufiné par son auteur, le lecteur s'interroge. Certains éléments appelaient sans doute une correction - de celles qu'effectue normalement le réviseur d'une revue ou d'une maison d'édition -, d'autres nécessitaient peut-être une retouche plus substantielle - de celles qui éclairent mieux la pensée. Dans les deux cas, il est d'usage que l'auteur donne son autorisation, intervienne activement dans le processus final. J'ai donc lu ce texte avec le souci de rectifier certaines fautes. Ces corrections mineures ne sont pas signalées. J'ai également tenu à effectuer certaines retouches afin d'éclairer mieux le sens et mes interventions sont alors signalées et expliquées en note. Micheline Cambron [Les notes de la correctrice apparaissent en italique dans le texte.]

${ }^{* *}$ Le texte a d'abord fait l'objet d'une conférence à l'université MoGill. 
contenu [d'une] culture publique commune* au Québec, surtout au Québec pluriel de la région de Montréal. La notion elle-même a été élaborée par plusieurs, en particulier par Gary Caldwell et moi-même', depuis 1990. Cette recherche est née d'une volonté de dépasser les «deux solitudes», empruntées à Rilke par Hugh MacLennan, devenues les pluri-solitudes avec la diffusion du multiculturalisme depuis 1971. Elle cherche à mettre en relief de façon structurée (Gestall) ce qu'a imprimé en chacun de nous, en termes de valeurs et de non-valeurs, le fait d'avoir vécu ensemble pendant plus de trois siècles, tout en reconnaissant que certains d'entre nous étaient ici avant les Français et les Anglais et que d'autres sont venus plus tard.

Pour le faire, je me sers de quelques études européennes sur l'intégration culturelle des immigrants ${ }^{2}$ et de quelques études canadiennes sur la culture d'ici3. En le faisant, je suis bien

[une] culture. Le choix de l'article indéfini trouve son sens dans la nature prospective de l'intervention.

1 Julien Harvey, "Culture publique, intégration et pluralisme», Relations, no 574, octobre 1991, pp. 239-241 et Cary Caldwell et Julien Harvey, «Le prérequis à l'intégration des immigrants; une culture publique commune», L'Action nationale, vol. 84, no 6, 1994, pp. 786-794.

2 J'utilise en particulier : Christian Jelen, Ils feront de bons Français, Paris, Robert Laffont, 1991 et Emmanuel Todd, Le Destin des immigrés, Paris, Seuil, 1994.

3 Surtout Marc-Adélard Tremblay, L'Identité québécoise en périh, Sainte-Foy, Éditions Saint-Yves, 1983; Gérard Bouchard, François Rocher et Guy Rocher, Les Francophones québécois, Montréal, Conseil scolaire de l'île de Montréal, 1991; Margaret Atwood, Essai sur la littérature canadienne, Montréal, Boréal, 1987 (d'abord pan en anglais sous le titre Survival, Toronto, Anansi, 1972); Northrop Frye, Divisions on a ground. Essays on Canadian culture, Toronto, Anansi, 1982; Léon Dion, $A$ la recherche du Québec, Québec, Presses de l'université Laval, 1987; Christian Dufour, Le Défi québécois, 
conscient d'avancer dans un territoire peu exploré et de compter sur votre critique et sur celle des lecteurs éventuels de nos travaux. Je définis la culture comme l'art de vivre, de façon originale, assez prolongée et généralement communautaire, la condition humaine universelle. Et je définis l'intégration comme un contact culturel intermédiaire entre l'assimilation et la juxtaposition, tenant compte des cultures en contact et constituant, avec le temps, une nouvelle synthèse et une nouvelle dynamique ${ }^{5}$. C'est surtout à la pluridimensionalité de la culture que je m'intéresse ici : toute culture comprend des connaissances, des normes sociales, des comportements, une sensibilité, une esthétique, des façons de percevoir et de vivre les appartenances, les institutions communes, l'association, l'image sociale du groupe ${ }^{6}$.

À ce stade, je crois nécessaire d'ouvrir une parenthèse à propos d'une étude récente d'un «scholan de la jeune génération, Dimitrios Karmis, que j'ai déjà cité. Remarquons d'abord qu'il conteste deux études assez récentes sur l'identité et donc la culture québécoise, celles de Léon Dion et de Christian Dufour?. Il reproche à Dion de donner trop de place à la littérature comme lieu d'exploration de la culture au sens anthropologique du terme et de ne pas écouter des auteurs plus jeunes comme Neil Bissoondath, Ying Chen, Sergio Kokis, Dany Laferrière ou Stanley Péan (p. 6). Je suis d'accord pour reconnaître que le livre de Dion date de dix ans (1987), mais je ne suis pas du tout

Montréal, L'Hexagone, 1989; Dimitrios Karmis, Identities in Québec. Between «la souche» and atomization, Montréal, Cahiers du Programme d'études sur le Québec, no 8, juin 1997.

4 Voir Relations, art. cit., 1991, p. 239 et note 1.

5 Ibid. et note 2.

$6 \mathrm{Ibid}$. p. 240 et note 4.

7 Par exemple, Hubert Guindon, Québec society, tradition, modermity and nationhood, Toronto, University of Toronto Press, 1988; Northrop Frye, op. cit., p. 66. 
d'accord sur une grande partie de la liste de remplacement proposée par Karmis : ce sont des citoyens du Québec, mais littérairement aucun d'eux n'est québécois. On me dit que des phénomènes semblables se produisent en Angleterre (Salman Rushdie) ou en France (Franz Kafka). Mais malgxé le prodigieux talent de ces écrivains, je ne puis pas les reconnaitre littérairement comme anglais ou français's. Quant à Dufour, j'admets que son premier chapitre est le meilleur de son livre, mais Karmis a tort de lui reprocher d'appliquer des catégories de la psychologie individuelle à la société; il n'y aurait pas de psychologie sociale si on ne l'avait fait abondamment jusqu'ici. Et il a tort de lui opposer Gadamer et son souci de la réactualisation constante, puisque des thèmes se retrouvent dans toute la littérature québécoise depuis ses débuts (la défaite de 1760, la répression de 1837-1838, la violence iroquoise contre Montréal dès 1642, etc.). Dans la partie positive de son étude, Karmis apporte des éléments importants : la distinction entre les valeurs convergentes et les valeurs communes (Charles Taylor), la division des identités nationales en trois catégories : civique, généalogique et culturelle-linguistique. Mais il s'engage dans des voies plus discutables quand il emprunte, plus qu'il ne le dit, au Pierre Elliott Trudeau des années 1960 sur le multiculturalisme comme idéal culturel du Canada et du Québec', ou quand il accepte le phuriculturalisme du Québec entre 1937 et 1945 selon Fermande Roy ${ }^{10}$, surtout quand il suit

8 Karmi, art. cit., pp. 5-9. Voir le rapport du colloque de l'Académie des lettres du Québec à Sainte-Adèle en 1992, Écrits du Canada franfais, vol. 79, 1993.

9 Pierre Elliott Trudeau, Le Fédéralisme et la société canadiennefrançaise, Paris, Robert Laffont, 1968; Karmis, art. cit., Pp. 14-15.

10 Fernande Roy, Histoire des idéologies an Québec au XIXe et XXe siècles, Montréal, Boréal, 1993; Karmis, art. cit., pp. 12 et 16. 
Michael Behiels sur la Révolution tranquille ${ }^{11}$. Sa conclusion, qui appuie chaudement l'émergence des identités collectives englobantes ("comprebensive collective identities), qui requièrent plus de communication et plus d'accueil des diverses communautés, non seulement au niveau des élites, mais de la part de tous, est juste ${ }^{12}$. Mais Karmis passe ainsi, sans justification, de la citoyenneté juridique québécoise, acquise après trois ans, à l'enracinement culturel, qui requiert l'adhésion à un centre de gravité communautaire, ce qui ne s'acquiert pratiquement jamais avant deux ou trois générations de vie dans un groupe. Même si elle fait avancer la question, la thèse de Karmis prend trop de risques du côté de l'atomisation multiculturelle et néo-libérale, qu'il veut précisément éviter.

Je me propose maintenant, malgré les quelques réticences de Karmis, d'explorer ce qui nous rassemble, ce qui fait un pays audelà de nos multiples cultures d'origine, ce que nous avons développé ensemble depuis plus de trois siècles. Je l'observe surtout chez des littératures des deux cultures anciennes d'ici. Et je divise en trois parties mes observations : la société et le pays, l'individu, la nature ${ }^{13}$.

\section{La société et le pays}

Nous sommes un pays, Québec ou Canada, qui n'a pas connu de révolution, contrairement aux États-Unis et à la plupart des pays d'Europe. La plupart de nos ancêtres, surtout

11 Michael D. Behiels, Prelude to Québec's Quiet Revolution, Montréal et Kingston, McGill-Queen's University Press, 1985; Karmis, art. cit., p. 17; voir Julien Harvey, Relations, no 516, décembre 1995, pp. 331332.

12 Karmis, art. cit., pp. 4 et 22-23.

13 Pour.le faire, j'utilise surtout les ouvrages cités à la note 3 . 
les Français, n'ont pas été des immigrants, mais ont été des envahisseurs, qui sont entrés sans grande lutte dans un pays dont l'étude de la préhistoire nous apprend que la population autochtone était à peu près celle des Amérindiens dans le Québec d'aujourd'hui (soit environ 60000 personnes). La seule exception est Montréal, dont la fondation fut rudement contestée par les Mohawks, une exception que les envahisseurs français d'alors ne semblent pas avoir comprise, étant donné que les Mohawks ne demeuraient pas dans la région. Une conséquence de ce fait (pas de l'exception) est que, dans la culture publique commune à tous les Québécois, la violence ne paie pas. Ce qui n'exclut pas que nous sachions être violents, mais exclut que nous le soyons impunément.

Nous sommes passés de l'âge baroque du XVIIe siècle au romantisme du XIXe siècle sans profiter de l'âge des Lumières, notre XIXe siècle étant une époque de lutte entre Français et Anglais, une époque d'isolement. Certains de nos historiens me semblent avoir raison quand ils reconnaissent que la formule des deux solitudes était la meilleure pour protéger les deux cultures $^{14}$. Si le «scholarshipm n'a pas de frontières, la culture en a et en avait encore davantage il y a deux ou trois siècles. Une conséquence considérable de cette double origine est qu'il n'y a pas de Canadien-type, ni de Québécois-type : il a toujours été possible ici, même à des personnes enracinées et cultivées, parfois depuis plus de deux siècles, d'ignorer complètement l'autre culture, qu'on soit anglophone ou francophone ${ }^{15}$. De plus, nous avons dû aller chercher l'Aufklarung ailleurs par la

14 Par exemple, Hubert Guindon, op. cit. et Northrop Frye, op. cit., p. 66.

15 Un exemple extraordinaire : Mordecai Richler, "Canadian identity" in Elliott J. Feldman, The Future of North America, Cambridge et Montréal, Center for International affairs, Harvard University and Institute for Research on Public Policy, 1979, pp. 755. 
suite, ce qui doit expliquer notre manque de grands philosophes et de grands théologiens.

Une autre conséquence de notre longue et souvent difficile histoire est que nous avons développé une mentalité de survivants, surtout devant la croissance considérable des ÉtatsUnis $^{16}$. Selon les tempéraments et les histoires personnelles, la vive conscience de notre fragilité prend quatre formes : certains nient être des survivants menacés mais insistent trop, d'autres l'admettent, parfois exagérément, d'autres l'admettent en refusant d'en jouer le rôle, d'autres enfin se servent de ce handicap pour devenir créateurs ${ }^{17}$. Un Canadien n'est jamais totalement victorieux; s'il risque de l'être, il se culpabilise. Chez les Canadiens français, la conscience d'être victime des "Anglais» se développe facilement, de même chez les Canadiens anglais, celle d'être victimes des Américains. Chez les Amérindiens, on se sent souvent victimes des deux groupes dominants, Anglais et Français. Et chez beaucoup d'immigrants, la conscience de survivant est endémique. Cette conscience de soi comme survivants rend les Canadiens modestes, mais facilement culpabilisables, incapables de développer cette mentalité de "conquérants de la frontière» que beaucoup d'Américains ont développée, souvent avec succès.

Beaucoup de ces traits majeurs de notre identité culturelle commune sont demeurés inconscients jusqu'à la Révolution tranquille (1960), certains disent jusqu'au Refus global du groupe de Borduas en 1948. En milieu anglophone, la conscience d'une identité analogue s'est développée également dans les années 1960; certains parlent d'un éveil provoqué par le Rapport Massey

16 C'est le titre original d'un essai déjà cité de Margaret Atwood sur la littérature canadienne.

17 Margaret Atwood, op. cit., pp. 36-42. 
et par la création du Canada Council en $1951^{18}$. Si bien que la compréhension de la Révolution tranquille comme une libération de la tradition, plus que du cléricalisme ou de la comuption politique, est commune aux deux cultures majoritaires au Canada et au Québec.

\section{L'individu}

Nous sommes un peuple qui n'a pas de mythologie, au sens strict du terme. Seuls les Amérindiens en conservent des fragments, ou certains immigrants récents qui sont encore en marge du courant culturel dominant. Les images littéraires des explorateurs, des colons, des pionniers sont surtout marquées par l'échec. Nous n'avons pas de héros individuels, contrairement aux Washington, Jefferson et Franklin de nos voisins. La culture francophone ancienne en avait glorifié, mais ils ont été mis en question et généralement oubliés, ou sont devenus des héros de l'échec ${ }^{19}$. Qui perçoit aujourd'hui Dollard des Ormeaux, les Martyrs canadiens ou les Pères de la Confédération comme des figures ancestrales dont on est fier? D'autant moins que les années de la Révolution tranquille nous ont fait abandonner l'histoire dans la formation scolaire, autant chez les anglophones que chez les francophones québécois. La raison en est sans doute une volonté inconsciente d'oublier un passé dont on avait honte, un passé pauvre, paysan et chrétien.

$\mathrm{Au}$ Québec, la famille est surtout perçue comme un piège auquel il faut à tout prix échapper. Nos téléromans ont régulièrement repris ce trait. Notre littérature, française et anglaise, représente souvent trois générations, celle des grands-

18 Voir Julien Harvey, «Les francophones québécois», Relations, janvier-février 1992, pp. 21-23 et note 13.

19 Gérard Bouchard et al., op. cit., pp. 60-61. 
parents durcis et oppresseurs, celle des parents obsédés par l'argent et culpabilisés, celle des enfants en lutte pour leur libération, souvent sans succès. Nous sommes loin de la famille américaine, même si parfois [le héros]* doit s'en échapper violemment pour repousser les frontières.

Il faut remarquer que, chez nous, la mort est aussi fatale : dans la littérature anglo-canadienne, elle arrive par la noyade et par le froid; au Canada français, souvent par le feu. Cela représente la victoire de la force mystérieuse, celle de Créon sur Antigone.

L'image de la femme dans notre littérature, surtout dans notre littérature ancienne des deux cultures, est souvent celle d'un ange de pierre ou de glace, mère féconde et volontaire, sans jeunesse et parfois sans âge mûr. Étrangement, la révolution sexuelle n'a pas fait disparaître cette image, que la télévision ramène constamment. Au Québec, la dimension religieuse, qu'elle soit profonde ou populaire, est très souvent exprimée par les femmes, dans toutes les formes littéraires et dans les beaux-arts.

\section{La nature}

Un premier trait frappant de notre pays est que la géographie y occupe plus de place que l'histoire, que l'espace vierge domine davantage que les concentrations urbaines, surtout maintenant que nous sommes presque tous urbanisés. Pratiquement partout dans notre littérature, anglaise et française, et dans notre peinture, surtout dans la peinture anglo-canadienne, la nature est montrée sous un jour violent et insensible. D'où une présence de la terreur, surtout dans la pensée anglo-canadienne,

* Il s'agit manifestement du béros. 
compensée par une fraternité plus grande avec la nature dans la tradition québécoise ancienne. Songez au folklore, aux chansons populaires et à des peintres comme Clarence Gagnon ou Cornelius Krieghof, opposés à la splendeur violente de la nature dans l'École des Sept. Dans l'Ouest canadien surtout, mais aussi au Québec, la nature apparait comme faite de courbes, que viennent contraindre les droites que tracent les humains : rails de chemin de fer, rangs, cadastre, clôtures. Avec ici encore une propension à reconnaître la victoire finale de la courbe sur la droite : la ferme abandonnée, le retour des broussailles. Notons que la nature est assez souvent féminine au Québec, mais que c'est plutôt une femme d'âge mûr. Enfin et surtout, il est indéniable que parmi les quatre saisons, c'est l'hiver qui nous a le plus marqués : notre nordicité nous a profondément transfơmés.

Les animaux ont pris une place importante dans notre imagerie de la nature : alors qu'en Angleterre ou en France, ils sont des êtres humains déguisés (songez à Lewis Carroll ou aux fables de Lafontaine), alors qu'aux États-Unis on pense d'abord au chasseur, ici l'animal est un frère auquel on s'identifie. Chez les Québécois, l'animal est souvent dominé, comme les humains qui l'entourent (songez à Agaguk et Ashini de Yves Thériault). La culpabilité devant l'animal tué est caractéristique de notre imaginaire. Faut-il observer que l'un des éléments ambigus de l'image de l'Amérindien dans notre pensée et dans notre littérature est qu'il est proche de la nature violente et perçu comme violent et impassible comme elle?

[Mais les enjeux de l'adaptation culturelle sont toujours plus complexes qu'il n'y paraît. Au Québec] ${ }^{*}$, trois attitudes envers la nature se partagent le terrain de notre inconscient et de notre histoire, que nous soyons rattachés aux puritains de Nouvelle-

* Il y a assurément ellipse. Il manque la réserve que le premier terme de la phrase semble appeler. 
Angleterre, aux calvinistes écossais ou aux jansénistes français : tenter de vaincre la nature pour être généralement écrasé par elle, se fondre dans une nature pour également disparaitre, apprendre à s'insérer harmonieusement dans la nature pour apprendre d'elle une sagesse ${ }^{20}$.

\section{En guise de conclusion}

Si la politique et l'économie sont centralisatrices, la culture est régionale. C'est la raison principale pour laquelle les mass-média sont, par définition, toujours prisonniers de la politique et de l'économie. Et c'est ce qui rend si difficile une approche anthropologique de notre milieu. Il est facile de dire que le Québec est une démocratie libérale phuraliste et que c'est à ce cadre que devrait s'adapter ceux qui optent pour la migration au Québec.

J'ai tenté de dire plus précisément ce qui constitue le faisceau de valeurs vécues depuis longtemps par les Québécois de toutes origines, malgré les frontières linguistiques et culturelles. En faisant cette démarche, je cherche à définir en mêrme temps le cadre dans lequel se produit la rencontre culturelle entre Québécois de langue française, de langue anglaise, peuples

${ }^{20}$ Doit-on ajouter que, chez nous, les petits enfants aiment les gros animaux, les enfants plus âgés les petits animaux, les adolescents les animaux compagnons forts et les couples des substituts aux enfants ? Il faudra se demander si la pratique intense des sports d'hiver à l'extérieur changera notre rapport à la nature. Par exemple, on a depuis longtemps remarqué que la pensée et les arts anglo-canadiens et anglo-québécois ont la passion du mouvement et que seul le Québec français a pratiqué la nature-morte en peinture : deviendrons-nous plus contemplatifs ou moins contemplatifs? [Note de la correctrice : ce paragraphe trouve son sens en note.] 
amérindiens et nouveaux arrivants. Je n'ai pas développé les raisons pour lesquelles je crois que la juxtaposition en mosaïque multiculturelle est une illusion et, à la longue, une menace. Cela a déjà été démontré à maintes reprises ${ }^{21}$. Je considère par ailleurs que nous avons intérêt à mieux voir ce qui nous rassemble, et que les arrivants ont droit à la ressemblance plus encore qu'à la différence ${ }^{22}$.

21 Récemment, voir : Nous tous un soleil. Nos passés, notre avenir. Un projet d'éducation interculturelle, Montréal, Éditions Saint-Martin, 1997, surtout pp. 89-120.

22 Sur cette distinction, voir : Christian Jelen, op. cit., surtout pp. 4181. 